\title{
New International Academics’ Narratives of Cross-Cultural Transition
}

\author{
Sharon L Thomas ${ }^{1} \&$ Bunmi S Malau-Aduli ${ }^{2}$ \\ ${ }^{1}$ Tasmanian Institute of Learning and Teaching (TILT), University of Tasmania, Tasmania, Australia \\ ${ }^{2}$ School of Medicine, University of Tasmania, Tasmania, Australia \\ Correspondence: Sharon Thomas, TILT, University of Tasmania, Tasmania, Australia, 7250. Tel: 61-3-6324-3350. \\ E-mail: Sharon.Thomas@utas.edu.au
}

Received: March 5, 2013

Accepted: March 22, 2013

Online Published: March 25, 2013

doi:10.5430/ijhe.v2n2p35

URL: http://dx.doi.org/10.5430/ijhe.v2n2p35

\begin{abstract}
Increasing numbers of academics world-wide are migrating as higher education institutions internationalise. Yet academics' experiences of cross-cultural transition remain under-explored, especially in comparison with students. This small-scale narrative study, employing focus group interviews, aimed to explore the cross-cultural transition experiences of international academics at one multi-campus university in regional Australia. This research was not institutionally-driven. Rather, it was instigated by the researchers out of concern for the welfare of new international academics at their institution. The findings are compelling, some of which underscore existing research findings of other migrating groups - for example, the complex, challenging, highly individualised nature of cross-cultural transition experiences. Some findings, however, are unique to this group of academics - for example, the 'culture of silence' that permeated most aspects of their professional lives as well as the challenges inherent in developing a professional identity in a small, isolated, parochial community. These latter findings are disquieting as they highlight a gap between policy and practice within the university. More disturbingly, they are resonant of the neoliberalist ideology currently dominating higher education where hyperindividualism and survival-of-the-fittest mentalities erode collegiality. There are salutary messages for the myriad groups who work in higher education institutions about the 'cost' associated with an absence of comprehensive, systematic institutional transition support for international academics. Recommendations specifically aimed at new international academics include: a revision of workload models; general and pedagogically-specific induction workshops; professional learning (cross-cultural transition) workshops for support staff and senior management; and the establishment of support groups for the academics and their families.
\end{abstract}

Keywords: Internationalisation, Academics, Cross-Cultural transition, Higher education, Narrative, Neoliberalism

\section{Introduction}

If one lives where one was born and bred, the continuity

of one's existence gives it and oneself and one's

environment... a subdued, flat, accepted reality. But if...

one suddenly uproots oneself into a strange land and a

strange life, one feels as if one were acting in a play or

living in a dream. And plays and dreams have that curious

mixture of admitted unreality and the most intense and

vivid reality.

\section{(Leonard Woolf, Growing)}

Movement of people between cultures has reached unprecedented heights during recent decades and will undoubtedly continue to expand (Cetron \& Davies, 2008). One outcome of this accelerated human movement is that educational institutions are now 'internationalising' as globalisation becomes a reality (Jackson, 2008; Knight, 2005). Internationalisation, as a term, is variously defined and understood. Put simply, however, it relates to the incorporation of an international and intercultural dimension into all aspects of higher education institutions, including, but not confined to: policy development, recruitment (of staff and students) and the preparation, delivery and outcomes 
of a program of study (Leask, 2009). Recent literature suggests that, over the last two decades, research on internationalisation has focussed primarily on activities at an institutional level and on the experiences of international students; research on the staff experience is under-represented (Saltmarsh \& Swirski, 2010; Sanderson, 2011). This is of some concern in the Australian context given that Shaikh (2009) has identified Australia as among the top destinations for "migrating academics" over the last three decades (p.16). Furthermore, the Review of Higher Education (Bradley, Noonan, Nugent \& Scales, 2008) identified that in 2006 over 40 per cent of Australian academic staff were born outside Australia and, disturbingly, that there was a high turnover of staff within that group (p. 24). Comparatively, at the University of Tasmania (UTAS), the site of this current study, approximately 15 percent of academics in 2012 were classified as 'international' (A. Booth, personal communication, March 20, 2013). Current policy at UTAS seeks to significantly expand this aspect of their internationalisation policy (University of Tasmania, 2012). This highlights the timeliness and significance of exploring the experiences of NIAs and attempting to address their needs, both at a local level within the university and at a national level.

There was no institutional directive to conduct this study. It was instigated and funded (from a personal teaching award) by the researchers themselves. Informal stories shared with these researchers, by new international academics at UTAS, suggested there was a gap between policy and practice in regard to some aspects of the internationalisation agenda at the university. This study, then, was an opportunity to explore academics' lived experience of the internationalisation policy. In doing so, it sought to expand the burgeoning Australian research in the area of international academic migration. Specifically, the study explored the cross-cultural transition experiences of eleven international academics (in this study referred to as new international academics [NIAs]) at one university in regional Australia. While there was a broad, over-arching question driving this study - What are the experiences of new international academics at UTAS? - it was framed more specifically around the following three questions:

1) What factors affect the experience of NIAs?

2) What professional opportunities and challenges do NIAs encounter as they adjust to living in Tasmania, Australia?

3) What support systems/programmes do NIAs find most/least useful?

\section{Background}

The tangible benefits of the internationalisation of higher education are manifold, a situation acknowledged by Welch (1997) well over a decade ago. They include, at a pragmatic level, a source of qualified staff to replace an increasingly ageing academic workforce, and the potential for dissemination of new knowledge and skills. At cognitive and affective levels, the benefits include broadened perspectives on teaching, learning and scholarship, and the development of greater tolerance for diversity, all with the potential to breakdown "insular and narrow cannons of practice and ideology" (Welch, 1997, p. 324). Such benefits, however, are characteristically offset by costs, both personal and professional (Abel, 2002; Chronicle of Higher Education, 1987; Green \& Myatt, 2011; Pulido, 2002). One of those costs relates to the myriad challenges posed by cross-cultural transition.

A wealth of literature has highlighted that transition between cultures (typically referred to as culture shock) including when it is voluntary - is characteristically, although not exclusively, challenging (see, for example, Saltmarsh \& Swirski, 2010; Ward \& Rana-Deuba, 1999). Introduced into cross-cultural literature by anthropologist Oberg $(1954,1960)$, culture shock is essentially a response to contact with a new culture. It is predominantly characterised by anxiety -feelings of loss, frustration and confusion - resulting from the loss of familiar cultural signs, symbols and social rules. The challenges associated with culture shock are complex, impacting on individuals affectively (psychological health and well-being), behaviourally (skills and functional fitness) and cognitively (thoughts, perceptions, attitudes, values and beliefs) (Ward, Bochner \& Furnham, 2001). Recent research has underscored these findings from the last half century, suggesting that the effects of culture shock are - despite globalisation - a relatively constant phenomenon (see, for example, Edwards-Joseph \& Baker, 2012; Fisher, 2011).

Cross-cultural transition challenges for NIAs are multi-layered. Not only do they face the generic difficulties involved in cross-cultural transition, they also face challenges specific to the field of higher education. These complex challenges commonly include: identity, isolation, language (both lingua franca and academic-specific discourse), spouse/family disenfranchisement, contending with unfamiliar social norms and education systems - in particular, adjustment to a culturally-specific approach to pedagogy, and perceived disparities in treatment by colleagues and institution (Abel, 2002; Clifford \& Henderson, 2011; Collins, 2008; Peterson, 2004). Furthermore, these NIAs often find it troublesome acquiring tacit knowledge and recognising the hidden expectations within their new environment (Cooper \& Stevens, 2002; Riskin, Ostendorf, Cosman, Effros, Li, Hamami \& Gray, 2004). Despite the highly resilient nature of some NIAs, recent research suggests that the capacity of these NIAs to contribute 
productively to the learning and teaching and research outcomes of their respective universities is compromised as they manage these myriad challenges associated with cross-cultural transition (Green \& Myatt, 2011; Saltmarsh \& Swirski, 2010). It is not uncommon for academic institutions to attempt to ameliorate these transition challenges by offering orientation programmes. These programmes, however, are usually one-off, focus primarily on institutional policies and procedures and rarely address the specific needs of NIAs (Gibbs, Gold \& Jenkins, 1987; Jocoy, 2006). Furthermore, "parochialism, prejudice and institutional inertia" (Welch, 1997, p. 324), can contribute to feelings of alienation and isolation amongst these academics - a claim that is consonant with the findings from this current study.

\section{Context for this Study}

This study was undertaken in 2011at UTAS, a multi-campus university located in regional Australia. Like many other higher education institutions world-wide, UTAS has an explicit internationalisation agenda, part of which involves employment of staff from international contexts. However, the experience of staff from international contexts relocating to UTAS remains unexplored. A number of factors motivated the desire to investigate this unexplored space. First, both authors have personally experienced cross-cultural transition and have regularly engaged in informal discussion with international colleagues at UTAS about their (mostly) challenging experiences. Second, one of the authors had recently investigated the experiences of international students' cultural adjustment at UTAS (Malau-Aduli, 2011) and the outcomes of that study, coupled with the breadth and depth of cross-cultural transition research over the last half century, made it appear axiomatic that international academics new to UTAS were likely to experience challenges in their transition to their new culture generally, and their work environment at UTAS, specifically. Finally, one of the authors, an academic developer at UTAS, was well positioned to be proactive in providing professional development to address the cross-cultural transition challenges that were expected to emerge from the current study.

This study therefore aimed to explore the experiences of NIAs - both opportunities afforded and challenges faced as they attempted to acculturate in their new environment. It was anticipated that the findings from this study would highlight opportunities to ameliorate the challenges, and reinforce opportunities, for future iterations of incoming international academics. In doing so it was predicted that not only their social and emotional well-being, but also their productivity in the workplace, would be enhanced. It was expected that the findings would ultimately inform policy (at both an institutional and departmental - referred to in this paper as 'School-based' - level) as well as practice.

\section{Methods}

\subsection{Research approach}

This study was conceived and designed within a constructivist paradigm. That is, there was an assumption on the part of the researchers that there are 'multiple realities' and an acknowledgement that knowledge is a social construction by individuals as a result of their idiosyncratic experiences (Denzin \& Lincoln, 2005). This study, then, sought to enhance multiple meanings rather than enhance certainty (Barone, 2001). It employed a narrative inquiry approach, a contemporary approach considered consonant with an exploration of experience, including the formation of professional identity (Chase, 1995; Clandinin, 2006; Clandinin \& Connelly, 2000) - the primary aim of this study. That narrative is considered by many to be central to human lives is clear from comments such as: "narratives [are] constitutive of humanness" (Adams, 2008, p. 176); "narrative [is] an ancient approach to understanding human affairs" (Ayers, cited in Hatch \& Wisniewski, 1995, p. 118); and “...narrative is present in every age, in every place, in every society...[it] is international, transhistorical, transcultural: it is simply there, like life itself" (Barthes, 1977, p. 79) (Thomas, 2012, p. 209). It is the symbiotic relationship between narrative (broadly conceptualised) and experience that specifically motivated the adoption of a narrative inquiry approach in this study: narrative is one our most fundamental ways of making meaning from experience. While the focus in narrative inquiry is on the particular, the unique and the idiosyncratic nature of experience, Clandinin and Connelly (2000) remind us of Dewey's assertion that individuals cannot be considered only as individuals; they are always in relation with others, always in a social context (Thomas, 2012). Thus, in this study, individual "experiences as expressed in lived and told stories" (Creswell, 2007, p. 54) provided greater insight into, and understanding of, broad social phenomena (Chase, 1995; Hatch \& Wisniewski, 1995). Specifically, the narrative approach employing focus group interviews, allowed the exploration not only of the NIAs' individual experiences of cross-cultural transition, but also an opportunity for meaning making in relation to their colleagues' lived experiences within their broader professional university and social contexts. In doing so, each NIA's lived experience was validated. Finally, it is narrative's unique capacity to represent human experience of time, as articulated by Ricoeur (1984), that affirmed its appropriateness for this study: the researchers expected, as a result of their own experiences and previous research, that participants, in sharing their 
cross-cultural transition stories, would be shaping and ordering past events as "retrospective meaning making" (Chase, 1995, p. 656).

\subsection{Participants}

Potential participants were NIAs (teaching, research or a combination) who had been born in, educated in (and possibly worked in) a country other than Australia (including other English-speaking countries) and who had been newly appointed at UTAS within the previous 18 months. They were identified through Heads of School (HoS). An email invitation, along with an Information Sheet detailing the rationale for the study, and a Consent Form, were sent to each prospective participant. Prior to commencement of the study, ethics approval was obtained from the Tasmanian Social Sciences Human Research Ethics Committee.

Eleven NIAs, who were within one and 18 months of commencing their new jobs with the university, were involved in this study. They comprised nine males and two females from eight schools/faculties (sciences and social sciences) across two campuses. Participants originated from the UK, India, Canada, Germany, US and Fiji. Three had been appointed into senior academic/research roles; they all re-located without their families. The remainder were appointed into lecturer positions; all re-located with family. Five reported that they had accepted positions lower in status than their previous jobs. Four indicated that their positions in UTAS were their first teaching roles - having come from research-focused positions - and four had previous overseas work experience and were therefore not new to the cross-cultural transition process. Thus, despite being a relatively small sample group, the 11 NIAs represented a mixed demographic.

\subsection{Data Collection}

Given that the primary aim of this study was exploring (rather than explaining) experience from the participants' perspective, semi-structured interviewing (through a focus group) was the method of data collection. Focus groups, rather than individual interviews, were chosen for two reasons. First, in keeping with Green's and Myatt's (2011) study, one of the anticipated outcomes of this study was the development of support networks amongst NIAs. Meeting other NIAs in these focus groups would go some way to helping that be realised. Second, literature suggests that there is an inherent desire in human beings to make meaning from their own and others' experience (Orbuch, 1997). Hearing others' stories of similar and shared experiences can be affirming and potentially help reduce some of the anxiety related to feelings of isolation. The decision to use focus groups was also a pragmatic one: their advantage in terms of efficiency (Farnsworth \& Boon, 2010).

Participants were invited to join one focus group interview (comprising four or five people) of approximately 60 to 90 minutes duration in December 2011. Two participants, because of timetabling difficulties, were interviewed independently. The interviews were jointly conducted by the researchers. One of the researchers was known to two of the eleven participants only, having worked with them in professional development courses earlier in 2011. At the time of interviewing no explicit 'power' relationship existed between this researcher/interviewer and the two participants: the researcher/interviewer had been responsible for formally assessing one of the two participants and this assessment had already been completed. Each participant was asked to share, in turn, their experience of cross-cultural transition - of moving from their previous country and relocating to UTAS. The question was deliberately broad and open-ended so that participants were not influenced to focus on any particular stage or aspect of the transition process. They were asked to speak uninterrupted for approximately 10 to 15 minutes (after Green \& Myatt, 2011). The uninterrupted nature of the story-telling was designed to construe inherent value upon each person's experience. Moreover, it reflected narrative's capacity to capture the holistic nature of experience rather than deal with experience as a set of discrete fragmented parts (Polkinghorne, 1988). Approximately 15 minutes at the end of the round of sharing was allocated for participants to ask questions (of clarification) of one another. This final questioning stage was aimed to allow participants to draw upon each others' experiences. This was considered a particularly significant (albeit brief) component of the interview as one of the potential outcomes of this study was, as mentioned earlier, to establish supportive networks amongst NIAs.

Interviews were audio taped using digital voice recorders and transcribed using a professional transcription service. Transcripts were anonymised through the use of pseudonyms (all Anglicised) and omission of identifying information, including details relating to country of origin - especially important given the relatively small size of the university. Participants were offered the opportunity to view interview transcripts and request the removal of any data they had personally contributed: three requested removal of data. 


\subsection{Data Analysis}

Data from the audio taped focus group and individual interviews were collated and independently analysed by the researchers, under the broad banner of analysis of narratives, one of two approaches advocated by Polkinghorne (1995, p. 13) as congruent with narrative inquiry. In an analysis of narratives approach, stories are collected and analysed, and common themes and concepts across all the narratives identified. Specifically, thematic analysis was undertaken, as described by Braun and Clarke (2006) - that is, identifying, analysing and reporting patterns within the data and organising (minimally) and describing that data in rich detail (2006). The data were initially subjected to inductive, bottom-up analysis where emerging themes were "data-driven" - that is, directly linked to the data, not fitted to pre-existing coding frames (p. 12). This was not a linear process, but rather a circuitous one where researchers first familiarised themselves with the data through repeated readings of transcripts and then coded and grouped participants' responses into key terms and phrases of related meaning. These codes were then synthesised to form broader themes, the titles of which reflected the 'essence' within. These themes were also devised to reflect the research questions underpinning the study. While initially semantic themes (i.e. the words spoken by the participants) acted as catalysts for the researchers' analysis, latent themes (i.e. underlying ideas and conceptualisations) formed the basis of the final decision-making in regard to themes (Braun \& Clarke, 2006, p. 13). Researchers then compared findings and through consensus, broad themes were devised: this allowed diverse and disparate experiences to be selected from the data and reported. This was a challenging stage - attaining an appropriate balance between too much breadth and not enough breadth. The allocation of sub-themes in places (titled from participants' verbatim quotes) helped alleviate this tension. In following this process, the researchers had attained, as Patton (1990) describes, both internal homogeneity and external homogeneity - coherence within themes as well as distinction between themes. Data were reported as a combination of verbatim quotes and summaries/paraphrasing of participants' contributions, connected by a narrative that referenced to literature.

\section{Results}

\subsection{Findings}

The stories shared by these 11 NIAs were complex and compelling. Yet Lincoln (1997) has long contended that it is a "realist pretense" to think the "whole story" can ever be told (p. 38). Challenging decisions, therefore, had to be made about what to leave in and what to leave out of the reporting of this study. Hoskins and Stoltz (2005) point out that, in a "world of "too muchness" the meaning-making process can become "overwhelming" (p. 98). In order to avoid being "overwhelmed", and mindful of Peshkin's (2001) warning that qualitative researchers risk being "paralysed" if they don't attempt to disconnect "natural interrelatedness" of data (p. 247), the data from the focus groups and individual interviews were interpreted based on three emerging themes. Those themes were: "pre-arrival experience'; 'professional adjustments'; and 'social adjustments'. Perhaps understandably, given the context of this study, 'professional adjustments' emerged as the dominant theme. While each theme can only provide a 'snapshot', they do, combined, effectively describe key elements of the NIAs' transition experiences. The themes are inter-related and overlap in function, illustrating the challenges earlier identified by Polkinghorne (1988) as inherent in any attempt to fragment personal experience.

\subsection{Emerging Themes}

\subsubsection{Theme 1: Pre-arrival experience}

When asked to talk about their 'move to UTAS', all participants, unprompted, started with pre-arrival information. Indeed, Michael's opening comment was, 'Let's start a bit before that.' This underscores decades of literature which identifies cultural transition as a process, not a state (see, for example, Meintel, 1973; Vidal, Valle, Aragón \& Brewster, 2007). It is also consonant with the findings from Green's and Myatt's (2011) study where this phenomenon is referred to as "the back story" (p. 36). Most participants" "back stories" were complex and intricate, adding to the challenge of myriad pre-arrival requirements. They reported mixed feelings - elation and anxiety - as they prepared for departure: this was despite the fact that four of the participants had extensive overseas experience and thus were not new to cross-cultural transition. Such paradox characterising cross-cultural transition is not uncommon (see, for example, Osland, 1995; Thomas, 2003).

Opportunity and possibility were clearly discernible in these NIAs' pre-arrival memories. Max spoke of 'being tired' of his previous professional position and disillusioned with lack of pay increases. Stuart referred to UTAS's policy of finding employment for spouses as 'one of the reasons' for migrating. Edward recognised the possibility of an improved quality of life: 
The very first thing when I saw the opportunity for a lecturer at (UTAS) I was very much interested in applying for it because I want to settle down with my family... my work...six weeks on, six weeks off, that was going on for years and my children were growing up and I wanted to be with them...I don't want to think of anything else.

Yet, it was the challenges that dominated participants' stories of their pre-arrival time. Some of these were external to the new employer (UTAS). Visa processing delays was one example. Max referred to the 'really wild time' of attempting to expedite his visa before he turned 55 years old - an age beyond which 'you have to be the Pope or something' to be allowed in to Australia. 'Cost' - time and money - was similarly recognised by Victor; he was incredulous that he had to undertake an IELTS test when he already possessed two undergraduate degrees in English. This was further complicated by the fact that he was 'from another country and was working as an expat in New Guinea' when he applied for the UTAS position.

At an institutional level, other challenges emerged - organising interviews via video links from developing countries, for example. Victor described as 'very difficult' the request to organise a video conference venue at short notice in New Guinea. The more emotional aspect of such difficulties was aptly captured by Edward:

We had a video conference which was an utter flop because my place is a small place where these kinds of activities don't happen with the video conference. So it was very difficult... Half the time it was interrupted; they could see me and I couldn't see them...sometimes I could hear them and sometimes I couldn't hear them...I was sweating. That was sometime in April and I was not aware of the result of the interview until September... I had one month ...everything within that time. I had to do IELTS and visa things and all that. I had to be on the double.

All participants had similar experiences of prompt and reliable pre-arrival support and communication from the UTAS Human Resources (HR) department - specifically in relation to the employment process and conditions of service. Chris appreciated HR's 'immediate response'; Max thought the recruiting was 'great'; and Stuart identified that $H R$ 'were very good in planning our trip'. Yet, the vast majority of participants referred to the extra difficulties they encountered because HR had not provided them with highly essential pre-arrival information about Australian housing, education, health care and transport systems. Comments included:

Yes, there are a few problems with Human Resources in the sense that (every country does this) they always think that everybody knows how everything works and they don't think in actual fact, it is a bit different... What they should have done for international people is have just a little packet of things that they give you of information, what you need to know... How the health system works here, education ...transport, pensions. (Aaron)

We ended up buying a book in (our native language) called 'Migrating to Australia'.... We needed to know where to go for medical insurance, we needed to know how to buy a car and how everything works... More information from the University could have been helpful. (Stuart)

For those who travelled with their families, pre-arrival challenges were more pronounced. Ethical and values-based decision-making compounded the organisational aspects highlighted above. Edward, for example, described being ' in a dilemma' about whether to accept the job because of his daughter's potentially interrupted education. 'If my daughter doesn't complete her grade 10...what then, what next? We don't know what will happen when we come here...All those kinds of doubts arise in our minds.'

Thus, pre-arrival experiences for these NIAs were simultaneously exciting, time-consuming, worrying, frustrating, perplexing, costly (emotionally as well as financially) and well supported by the host country institution. Arrival in the new country posed another set of complex experiences as the professional landscape came to dominate these NIAs' lives.

\subsubsection{Theme 2: Professional adjustments}

\section{"No after sales service"}

All participants in this study experienced considerable demands adjusting to their work environment, albeit varying in intensity. Responses ranged from adjustment being a 'learning curve' to 'feeling like an alien' to 'culture shock'. These professional adjustments included broad institutional-level issues (for example, research funding), School-based issues (for example, curriculum guidelines) and more personal work-related issues (for example, workload).

Formal support after arrival was rare for these NIAs, with one participant referring to the situation as 'no after sales service'. Most were in agreement about the limited HR support they received upon arrival. This stood in stark contrast to the prompt, reliable service they had received in relation to their work positions prior to arrival. They 
indicated that they were frustrated trying to navigate through the work system with very little or no assistance from HR or Schools.

The usual route is to go and see your HR person on the first day... "NO"...the girl in HR said, "No, we don't want to see him"...So HR could have smoothed this all over, but they just don't want to know you once you have arrived on campus. They are fine while they sort you out and get you and appoint you somewhere to stay but beyond that they don't want to know. (Michael)

I feel really welcome at the school, but with HR, ah, it is sort of a different story. (Stuart)

This is consonant with Shaikh's (2009) exposé of the paradox inherent in NIAs being "widely scrutinised" during recruitment but, seemingly, "rarely... appreciated or observed by their foreign hosts" (p. 26).

Interestingly, Chris, a senior academic, acknowledged that while he received 'appropriate support' from HR after arrival, 'many of (his) staff (did) have issues'.

School-based orientation programs were organised for some of the participants, where they were provided with copious amounts of paperwork and information about contact persons, but they felt abandoned afterwards, 'blundering around' and discovering things 'by accident or default' or 'trial and error basis'. The programs were not perceived as particularly useful as they didn't provide the institutional knowledge that is often invisible or hidden from easy access - a situation aptly represented by the 'iceberg' metaphor of culture (Jiang, 2000). They expressed feelings of alienation and confusion, being left to 'figure out many things by (them)selves', especially at staff meetings where acronyms and unfamiliar terminologies were constantly used. As Max reported, 'There are so many acronyms. You just sit there and go, "I have no idea what they're talking about". Ernest, too, ruefully recognised that his Head of School, for instance, 'did not have much time to spend with (him)'. They indicated that it took up to six months before they could adjust and integrate into the system, a temporal marker identified in other studies of cultural transition (see, for example, Adler, 1981; Vidal et al., 2007). One of the participants reported that he didn't know about the HR website and available resources until after 12 months of commencing his job.

There was also tension felt in having to master and use the appropriate discourse in order to gain membership into the academic community, a concept well supported in literature for all new academics, regardless of international backgrounds (see, for example, Becher \& Trowler, 1989). They indicated that some of the problems could have been avoided if Schools had established adequate support mechanisms for them.

I didn't even know there was a staff meeting and that I was supposed to turn up to. I felt it took six months to feel like I knew how the place worked. (Susan)

The way the University itself, the way they treat academic staff, you are given an office, you are sat there and expected to get on with things. I know nobody and I have no contacts in Australia, whatsoever. (Michael)

For those few fortunate to have the support of Heads of School, the situation was completely different.

I was lucky to have people around me at the department. Our Head of School was very keen and very diligent in going through a sort of checklist...in order to make sure that I fill in all the forms and we go through all the relevant procedures... The school made sure that my teaching in the beginning was not too extended and I have been offered support in conceptualising my courses and I think that should work but again that is specifically School, that is, not an initiative of the University. (Stuart)

Gaining membership in the academic community was also related to implicit expectations within Schools. Some absorbed these expectations while others rebelled. For Susan, for example, the unwritten work ethic of 60 to 80 hours per week in her School appeared 'untenable':

I actually said, "I'm not doing that". I will do what I can in my 29 hours per week but I am not working Sunday afternoons... That is why I work part-time, but the precedent from the top is, this is what you do and he does it and so everybody is expected to do it...Either people are too scared or, I don't know. People just end up doing it.... One of my colleagues said, "I go home, I work from 9 until 1 every night"...I am like, "What about sleeping or going out?"

Conversely, for Edward, being asked to teach classes at very short notice, resulted in him acquiescing, declaring that he just 'took it' and 'kept (his) mouth shut and did whatever (he) was asked to do'. Out of frustration, Edward began speaking with some of his colleagues and was surprised to find that they 'had faced similar issues...but nobody spoke about it.' A culture of silence had perpetuated Edward's anxiety.

A number of the participants made specific reference to "assumptions" - the inherent belief that they would either find it out for themselves or simply that everything was obvious. For example, Susan made reference to the fact that 
she didn't even know how she got paid and Aaron expressed confusion over differing meanings of 'Defined Benefit' in superannuation in his home country. While it may have seemed obvious to 'insiders', it was challenging for the NIAs as 'outsiders' to make sense of their new professional environment. Oberg's (1960) formative suggestion that sojourners and migrants are perpetual 'outsiders', regardless of length of stay in a country, appears timeless.

Assuming is the right word...everyone thinks that you know what is going on, so you kind of blunder around... You have got to do your own due diligence, which is tough, by the way, if you are a complete outsider. (Max)

There is an assumption that you know everything...they all think that why do you have to explain anything because it is OBVIOUS... My boss is very good, but I think he just makes assumptions that people know everything that happens in the school. (Susan)

None of the participants suggested that such 'negligence' was deliberate. Rather, they recognised it as being reflective of Hall's (1959) seminal insight: "culture hides much more than it reveals, and strangely enough what it hides, it hides most effectively from its own culture" (p. 53). As will be discussed in the next section, many UTAS staff have been born in Tasmania and have studied and worked in the same institution much of their lives. They are, therefore, often 'blind' to the idiosyncratic ways of their professional and social culture. Extensive use of uncommon acronyms and limited socialising with peers are two such examples highlighted by the NIAs in this study.

"Little girl lost"

There were varying experiences of informal support reported by these NIAs as they attempted to navigate their way through the professional maze. Max, for example, expressed surprise that on his campus, socialising with peers happened just once a month through a centrally organised event. Unsurprisingly, the degree of informal support was directly related to the ease of acculturation. Feeling 'pretty much not welcome' by colleagues who '(did) not acknowledge that you (were) there' hindered the adjustment process for one participant. In contrast, mirroring Chris's experience with formal HR support discussed earlier, senior NIAs had more informal professional support in comparison to their junior colleagues, something they readily acknowledged as being directly related to their position.

I know this very kind lady in my department, like I am this little girl lost, but she took me under her wing. (Susan)

I have found people to be tremendously helpful, very, very friendly. I haven't had any of those sorts of problems. It might be because I came in as one of two professors in this research institute and as a result there are people there who will help me with any of the problems. (Aaron)

I always sort of wondered, well, maybe if I came in at a lower level, they would be thinking, "Oh, why is he bothering me again?" (Stuart)

Junior NIAs who perceived their supervisors and colleagues to be supportive experienced faster and better adjustment than their counterparts. Also, those in supportive environments had lighter teaching workloads and were provided relevant resources.

I am replacing (name of colleague) so she was really very good to me and she explained everything very well before handing over her position to me and I had some resources to start with also...So I didn't have any problems with teaching here or in getting started... (Tracey)

I was assisted a lot by my other colleagues. My senior supervisor assisted me in showing me around and helping me settle down in my workplace and also I was fortunate I was not really loaded up with a lot of responsibilities in teaching... They understood my situation and accommodated me with the load I had... It was good because I had during those first few months applied for our visas as well...(Victor)

Others, however, reported heavy workloads, one describing working life as 'an uphill struggle for the first year'. They reported that they were so busy preparing lectures and teaching materials that they didn't have the time, especially in the first six to twelve months, to find out about other beneficial programs and activities within the university.

I was running around in circles wondering what to do and what not to, taking some input from here and there...In 2011 I delivered seven units. (Edward)

In addition, NIAs who came from higher status positions to lower ones, reported more acculturation challenges than the others, a finding purported by Henderson (2009) to be reflective of some communities' challenge in accepting the cultural 'other' into previously local spaces. 
In my previous role, I was the head of a department, with 65 staff, and we had to have management plans, appraisals it was all kind of organised, and I was the head of that pyramid and now I am at the bottom of this pyramid and I think I feel just a bit lost in my career direction at this time. (Susan)

Informal support and mentoring, then, rather than a planned, supportive strategy, appeared to be ad hoc and serendipitous for these NIAs.

"Separated by the same language"

Teaching posed its own set of challenges and learning opportunities for the NIAs as some of them entered academia for the first time and others came to understand that approaches to pedagogy are not universal (see, for example, Merriam, 2007). According to Hofstede (1986), the teacher/student interaction is an "archetypal human phenomenon", "deeply rooted in the culture of a society" (p. 303) - unsurprising then, that these NIAs reported difficulties in adjusting to the difference in academic standards, grading systems and student behaviour. This was more pronounced for those from non-English speaking backgrounds. Edward, for example, commented, 'My assessment was all just for the sake of favouring students - like everybody else...I knew I was doing an injustice. It is against my principles and it is something I did not want to do at all'.

As Green and Myatt (2011) discovered in their exploration of the experiences of new international academics, some of the participants in this study felt that they were left to 'run the show' themselves. Susan, for example, felt 'isolated' developing and reviewing a Masters course by herself. Edward again: 'The unit outline is not known to me, the course plan is not known to me, the student is not known to me, nothing is known to me, yet I was asked to deliver this unit'. Many started lecturing without prior knowledge of the academic discourse and expectations and were 'embarrassed' to ask questions in fear that it would make them appear incompetent. The emotional cost to these participants was palpable.

I have won teaching awards in other schools, at other places as well, but ah, I had not a large class but I got the lowest teaching evaluations I ever got. (Max)

My morale started going down...I was a bit shocked because for 20 years I was working on board ships, nine of them as Chief Engineer and everywhere I excelled. So why is it I am not excelling here? ... What do they say, 'Two people separated by the same language' ...(Edward)

In keeping with the global trend towards the professionalisation of the teaching role of academics (see, for example, Ginns, Kitay \& Prosser, 2008; Quinn, 2003), UTAS mandates a structured program aimed at developing academics' learning and teaching competence. One participant was surprised to be told by her Head of School, 'You don't need to worry about that'. Another decided to leave the formal learning and teaching coursework until the end of his three year probationary period, unaware of the direct benefit of this professional learning opportunity and free from demands of his Head of School to enrol. Those participants who did complete the coursework found it highly relevant and useful. Their recommendation, however, was that this would have been more effective if accessed earlier rather than later - that is, before engaging in teaching activities.

We have a strong academic background...but we don't know the techniques of how to pass this on. So this is where the (learning and teaching) course comes into play and, in my opinion I was not given an opportunity...I should have been in the program before I started the lectures. So a little bit of orientation and these courses will help us a lot to organise ourselves much better - to align ourselves, our views and our experiences with university policies and other stuff. (Nick)

Differing research contexts similarly proved problematic for some of the participants. Aaron, for example, found the university's policy related to carry over of funds as 'destroy(ing) (his research group's) ability to conduct contract research'. He described as 'a real struggle', his efforts to come to terms with funding arrangements: 'It is easy to get research money in Europe...but the ARC grants are next to useless in my environment...' Similarly, the preparedness of students to conduct research was proving troublesome for some. Max described some PhD students' lack of basic knowledge as making it 'tough' for him, leaving him 'a little nervous', while Aaron claimed that his current $\mathrm{PhD}$ students 'would not have survived' in his previous institutions. Different ways of knowing and being both in teaching and in research, clearly created tension for all participants.

Tasmania's demographic - an ageing, homogeneous and predominantly unskilled population of approximately 500,000 (Australian Bureau of Statistics, 2010) - along with its isolated geography as an island state, posed unique challenges for many of the NIAs, especially those from North America and Europe. They were especially confounded by the complexities of attempting to establish a professional identity in this context. These well-travelled and experienced academics all commented that they were unprepared for the fact that many UTAS academics were 
'homebred' and had little or no cross-cultural exposure/experience, a situation 'that is really discouraged elsewhere' (Aaron).

I have never known a University where the career path seems to be graduation to retirement in one place. And people who are here don't leave. People who grew up, did their degree, their PhD, got a lecturing job, and they stay. And everywhere else I have been, people have travelled around, even if they have been elsewhere and come back, but here, people don't leave and so they are very tied to Tasmania and what is going on in Tasmania and it is almost like the rest of the world doesn't exist, very tunnel vision. (Michael)

This insular characteristic was identified as professionally troublesome by Susan who struggled to find practical placements/internships for some of her international students in the broader community. "We have (professionals) who say, "Can we have the ones who speak really good English"...and one who was working in a very rural, very hard-nosed Tassie mining community said that (the international students) "just wouldn't survive here for three weeks.",

This insular characteristic was also identified by one participant as being paradoxical - simultaneously advantageous and limiting. One the one hand, 'it creates a feeling of intimacy and community' but on the other, 'everyone knows everything that is going on here. It is very difficult for confidentiality to be maintained' (Chris). Compounded by being a one state university, this lack of confidentiality permeated professional organisations consistently peopled by UTAS alumni. As one participant identified, 'the grapevine works very effectively throughout Tasmania'. Creating and maintaining professional links thus became problematic:

But so and so have been to university together and so and so is married to so and so's brother and so and so's sister's cousin lives... and so on. And that is so in professional links here... You have to really watch what you say because it is somebody's brother-in-law. (Susan)

Another parochial bottleneck related to intra-state rivalry:

A particular downside that relates to my position is the north/south divide and the tension and debate that goes with it...It dominates a lot of discussions and I am not familiar with that type of dichotomy...It is an ongoing unresolved series of challenges. (Chris)

Thus, dichotomy - both geographical and psychological (in terms of insider/outsider status) - characterised all these NIAs' experiences.

Yet, despite the troublesome professional landscape described above, there was evidence of resilience. Some of the longer term participants felt better adjusted to the new environment after the first six months to one year. For others, having had the opportunity to reflect on their performance enabled them to effect the required changes and obtain better outcomes with greater satisfaction.

Because I know my faults, when I corrected my own faults and I can see results now. A lot of things have changed in this year which has given me a lot of satisfaction now because there was a stage where my I was getting zero job satisfaction. (Edward)

\subsubsection{Theme 3: Social adjustments}

Parallelling the exhausting professional adjustments for these NIAs, were equally demanding social adjustments for themselves and their families. As Susan reported, 'Apart from getting a job, (I) was finding somewhere to live, finding schools for our two children and doctors...' They reported varying levels of, and disparate experiences with, culture shock in relation to climate, language, cultural values and social infrastructure such as transport, housing, health and education. Michael commented, for example, 'We find it cold', while Aaron countered, 'I think the climate is fantastic'. Similarly, Susan said she had more friends than ever before, primarily as a result of meeting other parents at her children's school, while Michael reported that his wife had been 'very lonely'. For Aaron, the health system was particularly confounding: '(It) is very different from what it is in France, the Netherlands or Canada and it should be sort of explained to you how it functions'.

Accommodation emerged as one of the major obstacles for all participants, bar Chris - who visited Tasmania three months prior to his appointment and secured his housing. Seemingly illogical requirements such as being asked to provide real estate agents with Australian references confounded Tracey: 'Obviously it is not possible for us to know many people straight away after just coming...' Max struggled to 'get a grip on' what were considered 'the better neighbourhoods' to live in, while Aaron was horrified at landlords' rights:'... the Landlord has the right of coming in every three months and poking around your place which is illegal in most countries.' Both Edward and Victor were provided with two week's accommodation by the university, after which they were required to find their own 
accommodation. For Edward, the fourteenth day fell on December $25^{\text {th }}-$ Christmas Day. 'I moved into my rented home...no telephone connection, no internet connection, nothing, absolutely nothing, no electricity connection'. Stuart, similarly, was unable to secure internet connection or international phone call capacity through the service provider because he didn't have a credit history in Tasmania, something he referred to as 'a big lack of logic'. Two participants with previous extensive overseas experience commented on how helpful it had been at those locations to have staff especially dedicated to helping them find accommodation.

In relation to transport, Stuart expressed frustration about his inability to have his overseas driver's licence transferred to a Tasmanian one. The title page, written in his native language, contained two dates - one the expiry date and one the issue date. The public servant refused to transfer the licence as she couldn't read (native language). One of Stuart's local friends suggested it was 'probably because (public servant) had not met someone who was not from Tasmania before.' The solution lay in his wife's to return to their home country to have a number of documents translated.

Although seemingly counter-intuitive, the transition was equally challenging for those with cultural backgrounds similar to Australia, a concept initially explored by Babiker, Cox and Miller (1980) under the moniker "cultural distance'. Max, for instance, feared the prospect of being identified as a an 'outsider'. This resulted in him 'not want(ing) to talk in public...because all of a sudden it marks you as kind of "not from here".' Susan expressed a similar concern.

There is an assumption that if you are an English native speaker - Caucasian - that it is much easier for you to integrate into that culture but it is isn't often the case...I felt a little bit out of my comfort zone, even though I am a white English speaking person.

These comments are consonant with the findings of Richardson's (2000) study exploring the experiences of international academics living and working in Singapore and New Zealand.

Irrespective of background (English-speaking /non-English speaking), all participants reported feelings of isolation, although to varying levels. Feelings of isolation, along with personal adjustment and culture shock, were particularly influenced by the level of family adjustment. Nick, for example, recognised that his family was, at first, essentially 'locked in the home until (he) reached home each day'. For many, adjustment was moderated by community engagement, such as joining church groups or bushwalking and bike clubs. Most reported more support from people in the community and/or their School, who had originated from the same country. Nick, for instance, appreciated that 'there (were) friends from (his) country who (were) helping (his) family to settle down'. Susan found solace in a fellow national in her School:

I found it a little isolating at the beginning. I work on the same corridor as another fellow (from her country) and we kind of share a laugh sometimes for a bit light relief. We share a sense of humour. Maybe that's just nostalgic, missing where you are from maybe, because you are so far away. I suppose I realised all of a sudden I am living in Tasmania which is as far away from (home city) as it can possibly be.

Yet, for one of the participants and his Islamic wife, the 'culture shock' of academic and social life was so profound that they decided to leave:

Only a year and a half ago I came here and in about two or three weeks time I am going back. Yes, I have a permanent contract with probationary requirements here but I am giving that up and I am going back to a culture I prefer, I guess is the best way to put it...(Michael)

For Michael and his wife, the geographical isolation of Tasmania, coupled with its perceived capacity for insular thinking and behaviour, contributed to their decision to leave. The $\$ 3500$ return air fare, along with the requirement to provide a $\$ 12000$ visa deposit for their adult daughter to visit, for example, was prohibitive. They also struggled with the 'isolation' and the difficulty in 'getting off the island'. Particularly disturbing were suggestions of religious discrimination: '(My wife) has been very, very lonely... She gets followed around by store detectives...There are certain racial prejudices here... There have been various insults in cafes...'

Social adjustments, often invisible in the workplace, clearly contributed to the demand on these NIAs.

\section{Discussion}

As a small-scale narrative study designed to explore the experiences of international academics involved in cross-cultural transition in one university in Australia, it is not possible, nor even desirable, to generalise to a broader population. Despite this methodological caveat, a number of compelling findings have emerged that: complement existing cross-cultural transition literature; extend the burgeoning literature in the specific field of international 
academic transition; and raise broader, disturbing questions about the current global political climate in higher education.

Centuries of literature, both fiction and non-fiction, have explored the phenomenon of crossing cultures, predominantly from the perspective of students, missionaries and military and business personnel (see, for example, Storti, 2001). Yet, a number of factors characterise academics as a unique migratory group. Predominantly, they elect to travel; they have no host company or institution supporting them; and their move is often planned to be permanent rather than transitory (Richardson, 2000). Certainly, these unique aspects characterised many of the narratives shared by the NIAs in this study. Despite this, the findings from this study confirm findings from existing cross-cultural transition research of other groups. This suggests that some aspects of cross-cultural transition are experienced universally. Three of these will now be discussed.

First, cross-cultural transition in this study was experienced as a process. All narratives shared by the participants began with pre-arrival experiences and, for those who had been in Australia for approximately six months or more, a sense of resolution - primarily whether to stay or to leave - had been reached as they progressively tangled with the Hydra that is cross-cultural adjustment.

Second, all eleven participants, albeit in varying ways and to varying degrees, experienced culture shock. They found cross-cultural transition challenging - personally, professionally and socially. The pre-determinant for these challenging experiences was invariably change. 'Change' related at a cognitive level to: expectations (realistic or unrealistic, fulfilled or unfulfilled) (see, for example, Burgoon and Walther, 1990); identity (the link between self and other as well as individual and collective) (see, for example, Adler, 1975; Tajfel, 1978; Triandis, 1989); and values (both conscious and unconscious, reconciled and unreconciled) (see, for example, Christofi \& Thompson, 2007). At a behavioural level this 'change' related to personal and professional skills and communication. When considered in light of Argyle's (1969) conception of social interaction being a mutually skilled performance, the difficulties encountered by the NIAs in this study are unsurprising. At an affective level, the degree of stress experienced by these NIAs was evidenced through the consistent use of emotive terms, often specifically related to change in the level of social support they received (see, for example, Furnham, 1997). This finding gives credence to the notion that cross-cultural transition is better understood as a "psychological process" than a "physical relocation" (Arthur, 2003, p. 174). Adjusting to change, then, characterised much of the narrative sharing of these NIAs.

Third, and seemingly paradoxically, a finding from this study that is consonant with research findings from other cross-cultural transition groups is that each person's experience was highly individualised (see for example, Thomas, 2009). Haines (2013) explains this as a "fundamental dilemma" in research of migration: that is, people's lives are essentially social, embedded in the myriad social networks that sustain them, but once removed from those sustaining networks and entering new networks, their lives become highly individualised (p. 20). This individualisation is also partly explained by the range of variables that inevitably impact on the cultural transition experience: for example, reasons for migrating and experiences underlying those decisions; previous overseas experience; relationship with host nationals; and family support. While some of these variables are quantifiable, it was the qualitative nature of many of the variables that determined the uniqueness of each person's experience. Haines (2013) issues a salutary "warning" that such individualised experience may be obscured in the more generic higher education and migration literatures (p. 19). Underscoring this, Saltmarsh and Swirski (2010) call for "greater systemic recognition of the enormity of the transitional process experienced at an individual level" (p. 297). The narrative approach taken in this study has helped to highlight the personal, idiosyncratic nature of NIAs cross-cultural transition experiences.

One of the most provocative findings from this study that is specific to international academics relates to the "culture of silence' that surrounded and permeated so many aspects of these NIAs' transition experiences. That 'silence' was personally embodied: participants feared embarrassment and loss of face as well as rejection from colleagues if they asked too much or spoke out, affirming James Baldwin's (1964) assertion that "experience is a private and a very largely speechless affair" (p. 120). That silence was also departmentally/institutionally embodied: there was minimal evidence of a systematic School-based or institutional approach to supporting these NIAs. Rather, it was the exception rather than the rule, primarily $a d$ hoc and relied on the good will of colleagues, mirroring both Richardson's (2000) and Saltmarsh's and Swirski's (2010) earlier findings. While staff induction resources have recently been made available online at UTAS, they are generic in nature and not aimed specifically at the needs of NIAs. The ad hoc support is perhaps partially representative of reduced 'capacity' to comprehensively support new staff - a result of continually declining funding for universities in Australia. It is also representative of a gap between internationalisation as policy and internationalisation as practice. Perhaps more disturbingly, this silence could be 
symptomatic of the neoliberal ideology that is increasingly pervading higher education institutions. Caught in the bind of larger classes and revenue-raising, academics have less access to quality time to support and mentor new colleagues. Rather, as Giroux (2011) contends, academics are rewarded for work that is entrepreneurial, not for work that builds collegiality: "grounded in the culture of competitiveness and self-interest, corporate time reworks faculty loyalties. Faculty interaction is structured less around collective solidarities... than through corporate-imposed rituals of competition and production..." (p. 117). Considered through this lens, it is perhaps unsurprising, then, that the senior research academics in this study experienced more support than their juniors. Thus, the School-based and institutional silence these NIAs experienced is much more disquieting in its implications than simply framing a university too naïve, too busy, too financially stretched or too disorganised to effectively manage its international staff induction.

The 'silence' was also culturally and socially embodied, exemplified by many of the NIAs' feelings of isolation and confusion over different ways of knowing and being. The cultural and social embodiment of such silence can be partially explained by the existence of assumptions. Senior management and colleagues assumed that these NIAs would work things out for themselves and assumed that norms governing academic life at UTAS were obvious. When considered in light of Hall's (1959) earlier-discussed seminal claim that insiders are often blind to their own cultural practices and thus struggle to know what to share with newcomers, this appears, on the surface, to be a reasonable explanation. Indeed, this concurs with the findings of Saltmarsh's and Swirski's (2010) study, in which they call for "greater institutional awareness of cultural assumptions that inadvertently impede" the transition process for NIAs (p. 297). Clearly, awareness-raising is one possible mitigator for the current 'culture of silence' experienced by the NIAs and will be one of the recommendations arising from this study. When considered from a critical pedagogy stance, however, this cultural and social embodiment of silence is more troublesome.

Critical pedagogy theorists and writers promote and provide tools for the "hunting" and "unsettling" of such apparently common-sense assumptions (Brookfield, 1995, p. 2; Giroux, 2011, p. 3). The neoliberalist culture that now increasingly defines and frames - particularly - western higher education institutions, is characterised by hyperindividualism and a survival-of-the-fittest mentality as profit-driven practices - rather than socially just and ethically-driven practices - dominate the academic landscape. As Brennan and Naidoo (2008) highlight, such practices are recognised as impacting detrimentally on "things like trust, co-operation and community..." (p. 290, italics in original). Given, as they go on to suggest, that one of the basic tenets undergirding neoliberalist ideology is 'meritocracy' (i.e. your problems are your own fault and your privileges are things you deserve), the disturbing experiences of the NIAs in this study are clearly more complex, more opaque and more pervasive than, and less-easily explained as, hidden assumptions.

Another challenging finding from this study that relates specifically to NIAs is the degree to which the broader context into which they arrived, impacted on their experiences - their professional lives, in particular. Establishing professional identities in the new culture was problematic. While the 'host culture' has featured consistently as a variable in cross-cultural transition literature to date (see, for example, Rohrlich \& Martin, 1991; Torbiorn, 1982), little attention so far appears to have been paid to the challenges experienced by academics moving particularly from metropolitan western cultures to smaller, more isolated, insular, parochial contexts. Those NIAs in this study, most of whom were experienced cross-cultural sojourners, were variously disappointed, incredulous and partially professionally paralysed by this unexpected phenomenon. This finding underscores the narrative notion that personal lives can only be studied in relation to the contexts which endow them with meaning (Suárez-Ortega, 2012). At a broader social level, members of the public were, at times, non-accepting of and obstructive towards representations of 'otherness' and this raises questions about the degree to which perceptions of 'otherness' continue to distort thinking and practices, including in higher education institutions.

The 'cultural other', or an 'us and them' mentality, as framed by Said (1978) - traditionally perceived as a threat and something to be feared - has underwritten human history for thousands of years. Yet, its continued existence in the current age of globalisation seems less comprehensible. As Sanderson (2004) posits, "We in the West resonate more with a 'fear of the unknown' than anything approaching an inquisitiveness about it, a reasoned argument of it, an integration into it, or a veneration of it" (p. 20). Unfortunately, this inevitably leads to the development and policing of boundaries "which ultimately separate insiders and outsiders" (Sanderson, 2004, p. 8). For the NIAs in this study, boundaries had clearly been drawn between 'them' as 'outsiders' and their colleagues - and in some instances, the general public - as 'insiders'. Little in the university's social or political infrastructure was instrumental in helping the NIAs cross or blur those boundaries. Thus, the NIAs were navigating more than access to academic tribes (Becher \& Trowler, 1989); they were simultaneously attempting to gain recognition for and acceptance of their 
'otherness'. As Susan shared, sometimes people aren't that interested in where you come from or telling your experiences.

The above discussion provides an in-depth response to three research questions which framed this study. In sum, multivariate factors - personal, professional and social - affect the experiences of NIAs. Many of these are predictable and therefore, through awareness-raising, able to be ameliorated, although not eliminated. Second, all participants relocated to UTAS because of the professional opportunities afforded by such a move; however, the challenges inherent in adjusting to the new professional culture - particularly the 'silences' - overshadowed most of their experiences. Finally, support systems that target the direct needs of the NIAs and their families, in particular mentoring that decodes and demystifies professional and social sub-cultures, are perceived as most valuable.

\section{Conclusion}

Like the academics in the Phillips, Harris, Larson and Higgins (2009) study, the NIAs in this narrative study of cross-cultural transition moved from "comfortable spaces of knowing to uncomfortable places of becoming" (p. 1455). Their experiences were consonant with much existing cross-cultural transition literature. First, they were complex, challenging, and individualised. Second, for those fortunate to receive planned and personalised transition support, adjustment challenges were somewhat ameliorated. Third, transition was experienced as a process, with narratives invariably beginning prior to their arrival in the new country. What is unique to this study, however, is the fact that, for the vast majority of these NIAs, their experiences were also adversely characterised by a 'culture of silence' at personal, institutional and cultural/social levels, with School-based and institutional culture emerging as the most influential variable in their capacity to adjust. This is indicative of the neoliberalist ideology that now characteristically undergirds most western higher education institutions - an ideology that defines identities and relationships in terms of instrumental value (Marginson, 1999-2000; Barnett, 2013). It is also illustrative of the gap between the rhetoric of internationalisation at policy level and the lived experience of new international academics at practice level. Another unique finding was that, for some, particularly those experienced sojourners from western cultures, their experiences were directly and adversely influenced by the unique demography and geography of their new context, a situation suggestive of a pervasive discomfort with the 'cultural other'.

The implications of these findings are far-reaching for higher education institutions. The 'cost' of a largely unsupported transition can clearly be deleterious - to individual academics, their families and higher education institutions. Social and emotional well-being is compromised, inevitably leading to reduced productivity and impaired engagement with, and outcomes from, learning and teaching and research. The problems associated with the absence of a systematic, comprehensive institutional approach to inducting and mentoring NIAs has emerged in this study as a compelling theme, as it has in the nascent NIA literature over the last decade (see, for example, Collins, 2008; Gravois, 2005; Moody, 2004). If higher education institutions take seriously their intention to internationalise, there must be a considered, proactive approach to supporting NIAs in their cross-cultural transition.

A number of recommendations, aimed specifically at NIAs, have arisen from this study. First, workload models should be reviewed; juggling the multivariate demands of visas, housing, education, health and transport and a full teaching and/or research load has been shown from this study to be unsustainable for most of the NIAs. A lighter load for the initial semester would go some way to ameliorating the challenges associated with cross-cultural transition. Second, general and pedagogically-specific induction workshops and induction resources should be made available for all NIAs. These would help de-mystify the hidden assumptions currently embedded in day-to-day functioning of the university and unearth professional expectations related to learning and teaching and research. Third, professional learning (cross-cultural transition) workshops would alert support staff and senior management to the benefits of a staff mentoring system as well as the challenges inherent in any cross-cultural transition - a phenomenon often outside the lived experience of people who have largely resided in the same place - as well as the process by which cultural identities (their own included) are formed and maintained. Fourth, ideally, support groups could be established for the NIAs and their families to help mitigate their sense of isolation. These support groups could be in the form of social outings, 'coffee clubs' or play groups, for example.

While there is much in this paper that is troubling, it is written in a 'hopeful' vein, an approach that both Brookfield (1995) and Giroux (2011) advocate as fundamental to critical pedagogy. Raising awareness of, and by association, increased tolerance of, the plight of those engaged in cross-cultural transition and the ways in which our own and others' cultural identities are formed and expressed would, as Barnett (2013) contends, go some way towards reinstituting "the values and ideas deeply embedded in the university - of truthfulness, inquiry, critical dialogue, rational dispute and even iconoclastic endeavour." 


\section{References}

Abel, C. D. (2002). Family adjustment to American culture. New Directions for Higher Education, 117, 71-77. http://dx.doi.org/10.1002/he.42

Adams, T. (2008). A review of narrative ethics. Qualitative Inquiry, 14(2), 175-194. http://dx.doi.org/10.1177/1077800407304417

Adler, N. (1981). Re-entry: Managing cross-cultural transitions. Group and Organization $\quad$ Studies, $\quad 6(3)$, 341-356. http://dx.doi.org/10.1177/105960118100600310

Adler, P. (1975). The transitional experience: An alternative view of culture shock. Journal of Humanistic Psychology, 15(4), 13-23. http://dx.doi.org/10.1177/002216787501500403

Australian Bureau of Statistics. (2010). National regional profile: Tasmania. Retrieved February 5, 2013. [Online] Available:

http://www.abs.gov.au/AUSSTATS/abs@nrp.nsf/Latestproducts/6Population/People12006-2010?opendocumen t\&tabname $=$ Summary\&prodno $=6 \&$ issue $=2006-2010$

Argyle, M. (1969). Social interaction. London: Methuen.

Arthur, N. (2003). Preparing international students for the re-entry transition. Canadian Journal of Counselling, 37(3), 173-185. Retrieved May 19, 2009. [Online] Available: http://www.eric.ed.gov/PDFS/EJ672649.pdf

Babiker, I., Cox, J., \& Miller, P. (1980). The measurement of cultural distance and its relationship to medical consultations, symptomatology, and examination performance of overseas students at Edinburgh University. Social Psychiatry, 15, 109-116. http://dx.doi.org/10.1007/BF00578141

Baldwin, J. (1964). Notes of a native son. London: M. Joseph. (Original work published in 1955).

Barone, T. (2001). Touching eternity: The enduring outcomes of teaching. New York: Teachers College Press.

Barnett, R. (2013). Wanted: New visions of the university. University World News, 263. [Online] Available: http://www.universityworldnews.com/article.php?story=20130314135318787

Barthes, R. (1977). Image, music, text (S. Heath, Trans.). London: Fontana.

Becher, T., \& Trowler, P. (1989). Academic tribes and territories: Intellectual enquiry and the culture of disciplines. $\left(2^{\text {nd }}\right.$ ed.). Buckingham: The Society for Research into Higher Education and Open University Press.

Bradley, D., Noonan, P., Nugent, H., \& Scales, B. (2008). Review of Australian higher education: Final report. Canberra, ACT: Commonwealth of Australia.

Brennan, J., \& Naidoo, R. (2008). Higher education and the achievement (and/or prevention) of equity and social justice. Higher Education, 56(3), 287-302. http://dx.doi.org/10.1007/s10734-008-9127-3

Braun, V., \& Clarke, V. (2006). Using thematic analysis in psychology. Qualitative Research in Psychology,3(2). 77-101. http://dx.doi.org/10.1191/1478088706qp063oa

Brookfield, S. (1995). Becoming a critically reflective teacher. San Francisco: Jossey-Bass.

Burgoon, J., \& Walther, J. (1990). Nonverbal expectancies and the evaluative consequences of violations. Human Communication Research, 17(2), 232-265. http://dx.doi.org/10.1111/j.1468-2958.1990.tb00232.x

Cetron, M., \& Davies, O. (2008). Trends shaping tomorrow's world: Forecasts and implications for business, government and consumers (Part two). The Futurist, 42(3), 35-50.

Chase, S. (1995). Taking narrative seriously: Consequences for method and theory in interview studies. In Y. Lincoln \& N. Denzin (2003). (Eds.), Turning points in qualitative research: Tying knots in a handkerchief (pp. 273-296). Walnut Creek: AltaMira.

Christofi, V., \& Thompson, C. (2007). You cannot go home again: A phenomenological investigation of returning to the sojourn country after studying abroad. Journal of Counselling and Development, 85(1), 53-63. http://dx.doi.org/10.1002/j.1556-6678.2007.tb00444.x

Clandinin, D. (2006). Narrative inquiry: A methodology for studying lived experience. Research Studies in Music Education, 27, 44-54. http://dx.doi.org/10.1177/1321103X060270010301

Clandinin, D., \& Connelly, F. (2000). Narrative inquiry: Experience and story in qualitative research. San Francisco: Jossey-Bass. 
Clifford, V., \& Henderson, J. (2011). Shifting identities: International staff negotiating new academic identities. Refereed paper from the 34th HERDSA Annual International Conference $4^{\text {th }}-7^{\text {th }}$ July Coast, Australia.

Collins, J. (2008). Coming to America: Challenges for faculty coming to United States' universities. Journal of Geography in Higher Education, 32(2), 179-188. http://dx.doi.org/10.1080/03098260701731215

Cooper, J., \& Stevens, D. (2002). Tenure in the Sacred Grove: Issues and Strategies for Women and Minority Faculty, Albany: State University of New York.

Creswell, J. (2007). Qualitative Inquiry and Research Design. Thousand Oaks: Sage.

Denzin, N., \& Lincoln, Y. (2005). Methods of collecting and analysing empirical materials. In N. Denzin \& Y.Lincoln (Eds.), The Sage handbook of qualitative research ( $3^{\text {rd }}$ ed.) (pp. 641-649). Thousand Oaks: Sage.

Edwards-Joseph, A., \& Baker, S. (2012). Themes Caribbean overseas students perceive influence their levels of culture shock. College Student Journal, 46(4), 716-729.

Ellis, C., \& Bochner, A. (2000). Autoethnography, personal narrative, reflexivity. In N. Denzin \& Y. Lincoln (Eds.), Handbook of qualitative research $\left(2^{\text {nd }}\right.$ ed.) (pp. 733-768). Thousand Oaks: Sage.

Farnsworth, J., \& Boon, B. (2010). "Analysing Group Dynamics With the Focus Group." Qualitative Research 10,605-624. http://dx.doi.org/10.1177/1468794110375223

Fisher, R. (2011). Crossing cultures: Analysing the experiences of NZ returnees from the EU (UK vs non.UK). International Journal of Intercultural Relations, 35(6), 776-790. http://dx.doi.org/10.1016/j.ijintrel.2011.03.004

Furnham, A. (1997). The experience of being an overseas student. In D. McNamara and R. Harris (Eds.), Overseas students in higher education (pp. 13-29). London: Routledge.

Gibbs, G., Gold, J. R. and Jenkins, A. (1987). Fending for yourself: becoming a teacher of geography in higher education. Journal of Geography in Higher Education, 11(1), 11-26. http://dx.doi.org/10.1080/03098268708708982

Ginns, P., Kitay, J., \& Prosser, M. (2008). Developing conceptions of teaching and the scholarship of teaching through a Graduate Certificate in Higher Education. International Journal for Academic Development, 13(3), 175-185. http://dx.doi.org/10.1080/13601440802242382

Giroux, H. A. (2011). On critical pedagogy. New York: The Continuum International Publishing Group.

Gravois, J. (2005). Teach impediment. When the student can't understand the instructor, who is to blame? Chronicle of Higher Education, 51(31), A10-A12. [Online] Available: http://search.proquest.com.ezproxy.utas.edu.au/docview/214680887/fulltext/13D0563441E24CEC3D5/7?accou ntid $=14245$

Green, W., \& Myatt, P. (2011). Telling tales: A narrative research study of the experience of new international academic staff at an Australian university. International Journal for Academic Development, 16(1), 33-44. http://dx.doi.org/10.1080/1360144X.2011.546219

Haines, D. (2013). "More aware of everything": Exploring the returnee experience in American higher education. Journal of Studies in International Education, 17(1), 19-38. http://dx.doi.org/10.1177/1028315311433207

Hall, E. T. (1959). The silent language. New York: Doubleday.

Hatch, J. \& Wisniewski R. (1995). Life history and narrative: Questions, issues, and exemplary works. In J. Hatch \& R. Wisniewski (Eds.), Life history and narrative (pp. 113-135). London: Falmer.

Henderson, J. (2009). "It's all about give and take", or is it? Journal of Studies in International Education, 13(3), 398-409. http://dx.doi.org/10.1177/1028315308329788

Hofstede, G. (1986). 'Cultural Differences in teaching and learning.' International Journal of Intercultural Relations, 10, 301-320. http://dx.doi.org/10.1016/0147-1767(86)90015-5

Hoskins, M., \& Stoltz, J. (2005). Fear of offending: Disclosing researcher discomfort when engaging in analysis. Qualitative Research, 5(1), 95-111. http://dx.doi.org/10.1177/1468794105048658

Jackson, J. (2008). Globalization, internationalisation, and short-term stays abroad. International Journal of Intercultural Relations, 32(4), 349-358. http://dx.doi.org/10.1016/j.ijintrel.2008.04.004

Jacobson, R. L. (1987). 'Dollar's steep decline seen limiting overseas activities by U.S. academics', Chronicle of Higher Education, 34(14), December 2, A1 and A46-7. 
Jiang, W. (2000). The relationship between culture and language. ELT Journal, 54(4), 328-334. http://dx.doi.org/10.1093/elt/54.4.328

Jocoy, C. L. (2006). Surviving the first time through: A new instructor's views on designing and teaching economic geography and how mentoring early-career faculty can help. Journal of Geography in Higher Education, 30(3), 419-425. DOI:10.1080/03098260600927286

Knight, J. (2005). New rationales driving internationalisation. [Online] Available: http://www.bc.edu/bc_org/avp/soe/cihe/newsletter/News34/text002.htm

Leask, B. (2009). Using Formal and Informal Curricula to Improve Interactions Between Home and International Students. Journal of Studies in International Education, 13(2), 205-221. http://dx.doi.org/10.1177/1028315308329786

Leggo, C. (2008). Narrative inquiry: Attending to the art of discourse. Language and Literacy, 10(1), 1-21.

Lincoln, Y. (1997). Self, subject, audience, text. In W. Tierney and Y. Lincoln (Eds.), Representation and the text: Reframing the narrative voice (pp. 37-55). Albany: State University of New York Press.

Malau-Aduli, B.S. (2011). Exploring the experiences and coping strategies of international medical students. BMC Medical Education, 11(40). DOI: 10.1186/1472-6920-11 40

Marginson, S. (1999-2000). Living with the Other: Higher education in the global era. Australian Universities' Review, $\quad 42(2) \quad \& 43(1), \quad 5-8 . \quad$ [Online] Available: http://search.informit.com.au/fullText;dn=200104403;res=APAFT

Meintel, D. (1973). Strangers, home comers and ordinary men. Anthropological Quarterly, 46 (1), 47-58.

Merriam, S. \& Associates. (2007). Non-western perspectives on learning and knowing. Malabar, FL: Krieger.

Moody, J. (2004). Faculty diversity: Problems and solutions. New York: Routledge.

Oberg, K. (1954). Culture Shock. Indianapolis, IN: Bobbs-Merril Series in Social Sciences.

Oberg, K. (1960). Cultural shock: Adjustment to new cultural environments. Practical Anthropology, 7,177-182.

Orbuch, T. (1997). People's accounts count: The sociology of accounts. Annual Review of Sociology, 23, 455-478. http://dx.doi.org/10.1146/annurev.soc.23.1.455

Osland, J. (1995). The adventure of working abroad: Hero tales from the global frontier. San Francisco: Jossey-Bass.

Patton, M. (1990). Qualitative evaluation and research methods. (2 ${ }^{\text {nd }}$ ed.). Newbury Park, CA: Sage.

Peshkin, A. (2001). Angles of vision: Enhancing perception in qualitative research. Qualitative Inquiry, 7(2), 238-253. http://dx.doi.org/10.1177/107780040100700206

Peterson, P. (2004). Old paths and new directions for international education. Paper presented at Changing Concepts of International Educational Exchange and Mobility Conference, 24 July, Salzburg, Austria.

Phillips, D., Harris, G., Larson, M., \& Higgins, K. (2009). Trying on-being in-becoming. Four women's journey(s) in feminist poststructural theory. Qualitative Inquiry, 15(9), 1455-1479. http://dx.doi.org/10.1177/1077800409347097

Polkinghorne, D. (1988). Narrative knowing and the human sciences. Albany: State University of New York Press.

Polkinghorne, D. (1995). Narrative configuration in qualitative analysis. In J. Hatch \& R. W Wisniewski (Eds.), Life history and narrative (pp. 5-23). London: Falmer.

Pulido, L. (2002). Reflections on a white discipline. Professional Geographer, 54(1), $42-49$. http://dx.doi.org/10.1111/0033-0124.00313

Quinn, L. (2003). A theoretical framework for professional development in a South African university, International Journal for Academic Development, 8(1), 61-75. http://dx.doi.org/10.1080/1360144042000277946

Richardson, J. (2000). Expatriate academics in the globalised era: The beginnings of an untold story. Asia Pacific Business Review, 7(1), 125-150. http://dx.doi.org/10.1080/13602380000000006

Ricoeur, R. (1984). Time and narrative (Vol 1) (K. McLaughlin \& D. Pellauer, Trans.).Chicago: University of Chicago Press. (Original work published 1973) http://dx.doi.org/10.7208/chicago/9780226713519.001.0001 
Riskin, E., Ostendorf, M., Cosman, P., Effros, M., Li, J., Hamami, S., \& Gray, R. M. (2004). Mentoring for academic careers in engineering. Paper presented at Mentoring for Academic Careers in Engineering Conference, 4 October, Stanford University, California.

Rohrlich, B., \& Martin, J. (1991). Host country and reentry adjustment of student sojourners.International Journal of Intercultural Relations, 15(2),163-182. http://dx.doi.org/10.1016/0147-1767(91)90027-E

Said, E. (1978). Orientalism. London: Routledge and Kegan Paul.

Saltmarsh, S., \& Swirski, T. (2010). 'Pawns and prawns': International academics' observations on their transition to working in an Australian university. Journal of Higher Education Policy and Management, 32(3), 291-301. http://dx.doi.org/10.1080/13600801003743505

Sanderson, G. (2004). Existentialism, globalisation and the cultural other. International Education Journal, 4(4), 1-20. [Online] Available: http://iej.cjb.net

Sanderson, G. (2011). Internationalisation and teaching in higher education. Higher education Research and Development,30(5), 661-676. http://dx.doi.org/10.1080/07294360.2011.598455

Shaikh, S. (2009). A survey of migration of academics in Higher Education and their impact on host institutions. Reflecting Education, 5(1), 16-30.

Storti, C. (2001). The art of crossing cultures. ( $2^{\text {nd }}$ ed.). Yarmouth: Intercultural Press, Inc.

Suárez-Ortega, M. (2012). Performance, reflexivity, and learning through biographical-narrative research. Qualitative Inquiry, 19(3), 189-200. http://dx.doi.org/10.1177/1077800412466223

Tajfel, H. (Ed.). (1978). Differentiation between social groups: Studies in the psychology of intergroup relations. London: Academic Press.

Thomas, S. (2003). Living with paradox: The experience of living and teaching in another culture. Unpublished Masters Honours thesis. University of Tasmania.

Thomas, S. (2009). Coming home: University exchange students' narratives of cultural re-entry. Unpublished $\mathrm{PhD}$ thesis. University of Tasmania.

Thomas, S. (2012). Narrative inquiry: Embracing the possibilities. Qualitative Research Journal, 12(2), 206-221. [Online] Available: www.emeraldinsight.com/1443-9883.htm

Torbiorn, I. (1982). Living abroad: Personal adjustment and personnel policy in the overseas setting. Chichester: John Wiley \& Sons.

Triandis, H. (1989). The self and social behaviour in differing cultural contexts. Psychological Review, 96(3),506-520. http://dx.doi.org/10.1037//0033-295X.96.3.506

University of Tasmania. (2012). Open to talent: Strategic plan - 2012 onwards. [Online] Available: https://secure.utas.edu.au/staff-intranet/our-plan

Vidal, M. Eugenia Sánchez., Valle, Raquel Sanz, Aragón, M. Isabel Barba, \& Brewster, C. (2007). Repatriation adjustment process of business employees: Evidence from Spanish workers. International Journal of Intercultural Relations, 31(3), 317-337. http://dx.doi.org/10.1016/j.ijintrel.2006.07.004

Ward, C., Bochner, S., \& Furnham, A. (2001). The psychology of culture shock. East Sussex: Routledge.

Ward, C., \& Rana-Deuba, A. (1999). Acculturation and adaptation revisited. Journal of Cross-Cultural Psychology,30(4), 422-442. http://dx.doi.org/10.1177/0022022199030004003

Welch, A.(1997). The peripatetic professor: The internationalisation of the academic profession. Higher Education, 34(3), 323-345. http://dx.doi.org/10.1023/A:1003071806217

Woolf, L. (1961). Growing: An autobiography of the years 1904-1911. London: The Hogarth Press. 